\title{
Environmental evaluation of geopolymer bricks
}

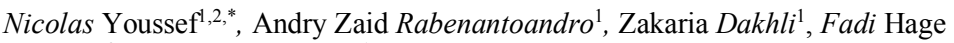 \\ Chehade $^{2}$, and Zoubeir Lafhaj ${ }^{1}$ \\ ${ }^{1}$ Centrale Lille, Civil Engineering, Cité Scientifique, CS 20048, 59651 Lille, France \\ ${ }^{2}$ Doctoral School of Sciences and Technology, Lebanese University, Lebanon
}

\begin{abstract}
This article presents the environmental assessment of geopolymer bricks produced from clay and waste bricks. The life cycle approach is the method used in this research to qualify, identify and compare the environmental impacts of geopolymer bricks and fired bricks. The results reveal that the manufacturing process of geopolymer bricks implies for the same compressive strength of fired bricks, a reduction of $\mathrm{CO}_{2}$ emissions by up to $55 \%$ for clay-based geopolymer bricks. This research checks the environmental interests of the application of geopolymerization technology in the production of bricks.
\end{abstract}

\section{Introduction}

Bricks are one of the widely used masonry units in the construction sector [1], with 1391 billions units fabricated per year [2]. The global building materials industry, such as those of bricks and cement, is responsible for a number of issues linked directly to a prominent social impact [3]. Conventional bricks are made of raw materials, such as clay, sand, plastic and non-plastic materials, and then fired in a kiln at a temperature exceeding $1000{ }^{\circ} \mathrm{C}[4]$. The use of fossil fuels is responsible for economic, energy, environmental problems and ecological issues [3]. For example, the production of one tons of cement requires the consumption of 1.7 tons of raw materials [3] and involves the emission of 0.8 tons of $\mathrm{CO}_{2}$ into the atmosphere [5]. However, in the production of building materials, a significant percentage of waste such as fly ash, waste bricks, blast furnace slag [6], results in many environmental issues. The process of recycling and recovering a large amount of waste bricks has become necessary to ensure environmental protection [7]. Geopolymerization is one promoted technique for recycling waste in the production of new building materials that meet both standards and application workability $[8]$.

The environmental impact of geopolymer-based building materials remains an open research question for researchers. $\mathrm{CO}_{2}$ emissions from the production of geopolymer materials have been presented in other studies from the environmental perspective [9]. During the preparation of cement clinker, calcination is the main step that consumes a large amount of energy and therefore releases a large amount of $\mathrm{CO}_{2}$. However, in the case of geopolymers, the dissolution of solids $\left(\mathrm{Na}_{2} \mathrm{O}+\mathrm{SiO}_{2}\right)$ is the main process that emits $\mathrm{CO}_{2}$. A recent study done by Duxson et al. in 2007, showed that $\mathrm{CO}_{2}$ emissions from geopolymer production are lower than those from ordinary cements [10]. This study was based on the alkaline activator as the main factor in $\mathrm{CO}_{2}$ emissions, and on the benefits of reduced water consumption and the absence of superplasticizers in the preparation of geopolymers. The results of this study show an $80 \%$ reduction in $\mathrm{CO}_{2}$ emissions compared to Ordinary Portland Cement [11]. Among all environmental assessments methodologies, Life Cycle Assessment (LCA) is a commons method to assess the environmental impacts of building materials.

The objective of this study is to provide a general analysis of the life cycle of geopolymer bricks production and to compare it with fired bricks. Not all life cycle stages of bricks are included in this analysis. The part studied includes only the brick's manufacturing process (from material extraction to drying).

\section{Materials and Methods}

For the LCA of geopolymer bricks, the main factors taken into account were: the materials used, the functional unit and the impact factors of each material used in the formulation of bricks. Four steps are studied in the LCA : Definition of the objective and fields of application, Inventory analysis, Impact analysis, Interpretation. Finally, the results obtained were compared with those of fired bricks often presented in the literature.

\subsection{Materials}

Seven formulations of geopolymer bricks were studied and compared to fired bricks. This part includes the inventory of materials used in the LCA. The solid materials used for the preparation of geopolymers are sand,

\footnotetext{
*Corresponding author: nicolas.youssef@phd.centralelille.fr
} 
clay, waste bricks (WB) and Ground blast furnace slag (GGBFS). The alkalis used are: sodium hydroxide $(\mathrm{NaOH})$ and sodium silicate $\left(\mathrm{Na}_{2} \mathrm{SiO}_{3}\right)$. Sodium hydroxide $(\mathrm{NaOH})$ was in the form of solid capsules, with a purity of $98 \%$, [12], [13]. The mass composition of sodium silicate is $27 \% \mathrm{SiO}_{2}, 8 \% \mathrm{Na}_{2} \mathrm{O}$, and $65 \% \mathrm{H}_{2} \mathrm{O}$ [14], [15]. Table 1 presents the compressive strength $(\mathrm{Rc})$ and $1 \mathrm{~m}^{3}$ composition of the formulations of geopolymer bricks for which the LCA evaluation was performed.

The compressive strengths of geopolymer bricks presents in the table 1 below were subjected to another study. This seven formulations were optimized with three properties : WB/GGBFS ratio, $\mathrm{NaOH}$ molarity and silicate/sodium hydroxide ratio used.

In this study, the formulations were prepared with different WB/GGFS ratios, an $8 \mathrm{M}$ molarity of $\mathrm{NaOH}$ and a silicate/sodium hydroxide ratio $=2$.

Table 1: Composition of $1 \mathrm{~m}^{3}$ of geopolymer bricks for the different formulations studied

\begin{tabular}{|c|c|c|c|c|c|c|c|c|}
\hline \multirow[t]{2}{*}{ FORMULATIONS } & \multicolumn{7}{|c|}{ SOLID AND LIQUID MATERIALS (G) } & \multirow{2}{*}{$\begin{array}{c}\mathrm{RC} \\
(\mathrm{MPa})\end{array}$} \\
\hline & Sand & Clay & WB & GGBFS & $\mathrm{NaOH}$ & $\mathrm{Na}_{2} \mathrm{SiO}_{3}$ & WATER & \\
\hline GCLAY & 827 & 827 & 0 & 0 & 92.83 & 93.77 & 293.04 & 20 \\
\hline GWB 1 & 827 & 0 & 827 & 0 & 362 & 44 & 137 & 38.96 \\
\hline GWB 2 & 827 & 0 & 661.6 & 165.4 & 362 & 44 & 137 & 44.78 \\
\hline GWB 3 & 827 & 0 & 496.2 & 330.8 & 362 & 44 & 137 & 51.92 \\
\hline GWB 4 & 827 & 0 & 330.8 & 496.2 & 362 & 44 & 137 & 62.3 \\
\hline GWB 5 & 827 & 0 & 165.4 & 661.6 & 362 & 44 & 137 & 89.91 \\
\hline GWB 6 & 827 & 0 & 0 & 827 & 362 & 44 & 137 & 72.48 \\
\hline
\end{tabular}

\subsection{Evaluation Methods}

\subsubsection{Functional unit}

In the LCA studies for materials, the functional unit used has a significant effect on the results obtained. The functional unit provides the basis for an environmental comparison. The methods used are different either in the quantity of the material or in the phases of the production process studied. However, most studies focus on a functional unit of $1 \mathrm{~m}^{3}$ of geopolymer materials and compare it with the same quantity of standard materials according to a given strength in the cured state [11]. The optimum results are obtained by using an identical final volume of the hardened materials as the basis for comparison.

The approach of this study is to reduce the brick's production phase. The analysis does not include all stages of the product life cycle but ends at an intermediate stage: the brick's production phase. The assumption taken into account is that, once the brick's blocks are prepared, the impacts during the rest of the life cycle (maintenance and demolition) will be similar for a geopolymer brick and a fired brick [16]. At the application level, the two compared bricks have similar properties in terms of freshness, durability and mechanical strength. Thus, the hypothesis of a reduction to an evaluation of the production phase is valid [16].

The functional unit applied is the $1 \mathrm{~m}^{3}$ of the formulation of geopolymer bricks. First, the LCA was realized for $1 \mathrm{~m}^{3}$ of geopolymer bricks using the impact factors of the materials used. Then, the $\mathrm{CO}_{2}$ equivalence comparison was based on the $1 \mathrm{~m}^{3}$ of geopolymer bricks in cured state.

\subsubsection{Impact factor}

The impact factors of a product represent its $\mathrm{CO}_{2}$ equivalence value. In the literature, impact factors are related to the production of materials. However, in the case of industrial waste or by-products, such as concrete waste, slag and fly ash, these factors are reduced to their treatment impacts [17]. Table 2 presents the impact factors of the materials used in the construction field and in the preparation of geopolymers [11]. 
Table 2: Global warming potential of the constituents of a standard concrete and alkali-activated materials [11].

\begin{tabular}{|lc|}
\hline Materials & $\mathrm{GWP}\left(\mathrm{kg} \mathrm{CO}_{2} \mathrm{eq}\right)$ \\
\hline Standard cement constituents & $8.44 * 10^{-1}$ \\
Ordinary Portland cement (OPC) & $7.49 * 10^{-1}$ \\
Superplasticizer & $4.29 * 10^{-3}$ \\
Coarse aggregates & $2.40 * 10^{-3}$ \\
Fine sand & $1.55 * 10^{-4}$ \\
Water & \\
Supplementary cementitious materials & $9.24 * 10^{-2}$ \\
Metakaolin & $3.51 * 10^{-2}$ \\
Limestone filler & $1.69 * 10^{-2}$ \\
Ground blast furnace slag & $5.26 * 10^{-3}$ \\
Fly ash & $2.93 * 10^{-3}$ \\
Kaolinite & $3.13 * 10^{-4}$ \\
Silica fume & $7 * 10^{-3}$ \\
Demolition waste & \\
Alkali-activators & $2.24 * 10^{0}$ \\
Soda powder (caustic soda) & $1.76 * 10^{0}$ \\
Sodium silicate $(2.0 \mathrm{WR}$, spray powder) & $1.24 * 10^{0}$ \\
Sodium metasilicate pentahydrate & $1.14 * 10^{\circ}$ \\
Sodium silicate (3.3 WR, 37\% solids) & $1.35 * 10^{0}$ \\
Phosphoric acid (1.2-1.6) & $4.16 * 10^{-1}$ \\
Ca(OH) - hydraulic lime &
\end{tabular}

\section{Results and discussion}

The environmental loads of clay and sand were considered. The extraction and preparation of these natural resources was also taken into account. The environmental burden of bricks or concrete waste included in the LCA is limited to the level of its demolition. Whereas, slags that are considered industrial waste, their loads are limited to the level of treatment essential for use in building materials. This method is applied in LCA studies of industrial waste [16]. The $\mathrm{CO}_{2}$ emission equivalence of geopolymer bricks was calculated according to the emission impact factors presented in Table 3 above.

Table 3: Calculation of $\mathrm{CO}_{2}$ equivalent emission for the formulation of geopolymer bricks (GClay) based on clay.

\begin{tabular}{|c|c|c|c|}
\hline \multicolumn{4}{|c|}{ Formulation of geopolymer bricks based on clay (GClay) } \\
\hline Composants & GWP KgCO 2 eq & Weight (Kg) & $\mathrm{Eq} \mathrm{CO}_{2}(\mathrm{Kg})$ \\
\hline Clay & 0.00293 & 827 & 2.42311 \\
\hline Sand & 0.00293 & 827 & 2.42311 \\
\hline Silicate & 1.14 & 92.83 & 105.8262 \\
\hline Hydroxide & 2.24 & 93.77 & 210.0448 \\
\hline Water & 0.000255 & 293.04 & 0.0747252 \\
\hline \multicolumn{2}{|c|}{$\mathrm{CO}_{2}$ equivalent emission } & \multicolumn{2}{|c|}{$\begin{array}{l}320.791945\left(\mathrm{Kg} / \mathrm{m}^{3}\right) \\
19.6957991\left(\mathrm{Kg} / \mathrm{m}^{2}\right)\end{array}$} \\
\hline \multicolumn{4}{|c|}{$\begin{array}{l}\text { GWP Kg CO} 2 \text { eq : Global Warning Potentiel } \\
\mathrm{Eq} \mathrm{CO}_{2}(\mathrm{Kg}): \mathrm{CO}_{2} \text { equivalent emission }\end{array}$} \\
\hline
\end{tabular}


This study examines the $\mathrm{CO}_{2}$ emission equivalence related to the manufacturing phase of geopolymer bricks. Therefore, this system includes the extraction of materials or import of waste, preparation of the mixture, transport, molding of samples and storage, while taking into account the energy consumed (fuel and electricity). As a result, the transport and placement phase of geopolymer bricks is excluded from our study. The functional unit used in this calculation is $1 \mathrm{~m}^{3}$ of the geopolymer brick's mixture, after the $\mathrm{CO}_{2}$ equivalence is determined for $1 \mathrm{~m}^{2}$ of geopolymer bricks in the cured state that is ready for application in construction. Figure 1 shows the calculation of $\mathrm{CO}_{2}$ equivalence for the formulation of clay-based GClay geopolymer bricks. The same calculation method is used for all other formulations studied.

Table 4 illustrates the results of the calculation of the $\mathrm{CO}_{2}$ emission equivalence of geopolymer bricks for the different formulations.

Table 4: $\mathrm{CO}_{2}$ equivalent emissions for different formulations of geopolymer bricks

\begin{tabular}{|llll|}
\hline Formulations & Eq CO2 $(\mathrm{Kg} / \mathrm{m} 3)$ & $\mathrm{Eq} \mathrm{CO} 2(\mathrm{Kg} / \mathrm{m} 2)$ & $\mathrm{Rc}(\mathrm{MPa})$ \\
\hline GClay & 320.79 & 19.69 & 20 \\
GWB 1 & 520.48 & 31.03 & 38.96 \\
GWB 2 & 522.12 & 31.13 & 44.78 \\
GWB 3 & 523.76 & 31.23 & 51.92 \\
GWB 4 & 525.39 & 31.32 & 62.3 \\
GWB 5 & 527.03 & 31.42 & 89.91 \\
GWB 6 & 528.67 & 31.52 & 72.48 \\
\hline
\end{tabular}

Note : $\mathrm{Eq} \mathrm{CO}_{2}\left(\mathrm{Kg} / \mathrm{m}^{3}\right): \mathrm{CO}_{2}$ equivalent emissions per $1 \mathrm{~m}^{3}$ of geopolymer bricks Eq $\mathrm{CO}_{2}\left(\mathrm{Kg} / \mathrm{m}^{2}\right): \mathrm{CO}_{2}$ equivalent emissions per $1 \mathrm{~m}^{2}$ of geopolymer bricks $\mathrm{Rc}(\mathrm{MPa}) \quad$ : Compressive strength

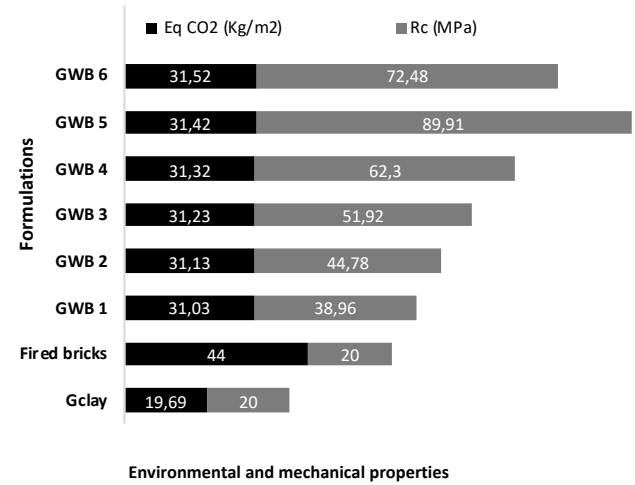

Figure 1: Environmental and mechanical propreties for different formulations of geopolymer bricks

For fired bricks, the $\mathrm{CO}_{2}$ equivalent is around $44 \mathrm{~kg} / \mathrm{m}^{2}$ [1]. The results of the $\mathrm{CO}_{2}$ equivalent of the geopolymer bricks, in Figure 1, clearly show the environmental benefit of these materials. The reduction in $\mathrm{CO}_{2}$ emissions reaches $55 \%$ in geopolymer bricks GClay, where clay is the main component along with sand. The $\mathrm{CO}_{2}$ emission reduction for all other waste bricks formulations is in the order of $29.5 \%$.

Thus, the level of $\mathrm{CO}_{2}$ emission reduction is much lower than the current environmental impact of fired bricks. In addition, based on the mechanical strength required for the brick-based construction sector, the mechanical advantage of this material is further demonstrated. Geopolymer bricks have shown a compressive strength largely sufficient for the construction of brick walls. This resistance has increased dramatically, with $89 \mathrm{MPa}$ for geopolymer bricks compared to $20 \mathrm{MPa}$ for fired bricks. 


\section{Conclusion}

The aim of this study is to determine the environmental impact of geopolymer brick production. For that, the environmental assessment of geopolymer bricks was presented. Seven formulations based on clay and waste bricks were used to produce geopolymer bricks. The results were compared with the traditional fired bricks. The concept of life cycle assessment (LCA) for geopolymer bricks was used to determine and analyze the environmental assessment. The $\mathrm{CO}_{2}$ emission equivalence was based on standardized impact factors and for a very well-defined functional unit. The results revealed that clay-based geopolymer bricks can reduce $\mathrm{CO}_{2}$ emissions by up to $55 \%$ compared to fired bricks and provide the required mechanical strength for structural works. Furthermore, geopolymers based on waste bricks reduce up to $29.5 \%$ of $\mathrm{CO}_{2}$ emissions with twice compressive strength as fired bricks. These results are an invitation to deepen the research. Geopolymer claybased bricks and waste bricks could also be a privileged alternative for fired bricks, on other aspects than the environmental and mechanical ones.

\section{References}

[1] A. A. Kadir and A. Mohajerani, "Bricks: An Excellent Building Material for Recycling Wastes - A Review," in Environmental Management and Engineering conference (EME 2011), Calgary, Canada, pp. 108-115, July 4-6, 2011.

[2] M. F. Zawrah, R. A. Gado, N. Feltin, S. Ducourtieux, and L. Devoille, "Recycling and utilization assessment of waste fired clay bricks (Grog) with granulated blast-furnace slag for geopolymer production," Process Saf. Environ. Prot., vol. 103, pp. 237-251, 2016.

[3] F. Puertas, "Waste glass in the geopolymer preparation . Mechanical and microstructural characterisation," J. Clean. Prod., vol. 90, pp. 397-408, 2015.

[4] H. Cheng, "Reuse Research Progress on Waste Clay Brick," Procedia Environ. Sci., vol. 31, pp. 218$226,2016$.

[5] A. Fernández-Jiménez, a. Palomo, J. Y. Pastor, and a Martin, "New Cementitious Materials Based on Alkali-Activated Fly Ash : Performance at High Temperatures,” J. Am. Ceram. Soc., vol. 91, no. 10, pp. 3308-3314, 2008.

[6] D. M. Roy, "Alkali-activated cements Opportunities and challenges," Cem. Concr. Res., vol. 29, pp. 249-254, 1999.

[7] L. Zhang, "Production of bricks from waste materials - A review," Constr. Build. Mater., vol. 47, pp. 643-655, 2013.

[8] J. Davidovits, "Geopolymers - Inorganic polymeric new materials," J. Therm. Anal., vol. 37, no. 8, pp. 1633-1656, 1991.

[9] A. Petrillo, R. Cioffi, C. Ferone, and F. Colangelo, "Eco-sustainable Geopolymer concrete blocks production process," Agric. Agric. Sci. Procedia, vol. 8, pp. 408-418, 2016.

[10] P. Duxson, J. L. Provis, G. C. Lukey, and J. S. J. van Deventer, "The role of inorganic polymer technology in the development of 'green concrete," Cem. Concr. Res., vol. 37, no. 12, pp. 1590-1597, 2007.

[11] C. Ouellet-Plamondon and G. Habert, "Life cycle assessment (LCA) of alkali-activated cements and concretes," Handb. Alkali-Activated Cem. Mortars Concr., no. December, pp. 663-686, 2014.

[12] A. Kumar Patra, M. Chowdhry, and B. K. Prusty, "Effect of synthesis parameters on the compressive strength of fly ash based geopolymer concrete," Int. J. Environ. Pollut. Control Manag., vol. 3, no. 1, pp. 79-88, 2011.

[13] M. M. Tashima et al., "Alkali activated materials based on fluid catalytic cracking catalyst residue ( FCC ): Influence of $\mathrm{SiO} 2$ / Na2O and $\mathrm{H} 2 \mathrm{O}$ / FCC ratio on mechanical strength and microstructure," Fuel, vol. 108, pp. 833-839, 2013.

[14] M. Sayed and S. R. Zeedan, "Green binding material using alkali activated blast furnace slag with silica fume," HBRC J., vol. 8, no. 3, pp. 177-184, 2013.

[15] M. M. Tashima et al., "New geopolymeric binder based on fl uid catalytic cracking catalyst residue ( FCC )," Mater. Lett., vol. 80, pp. 50-52, 2012.

[16] G. Habert, J. B. D’Espinose De Lacaillerie, and N. Roussel, "An environmental evaluation of geopolymer based concrete production: Reviewing current research trends," J. Clean. Prod., vol. 19, no. 11, pp. 1229-1238, 2011.

[17] C. Chen, G. Habert, Y. Bouzidi, A. Jullien, and A. Ventura, "LCA allocation procedure used as an incitative method for waste recycling: An application to mineral additions in concrete," Resour. Conserv. Recycl., vol. 54, no. 12, pp. 1231-1240, 2010. 